Check for updates

Cite this: Chem. Sci., 2018, 9, 5082

\title{
Enantioselective radical process for synthesis of chiral indolines by metalloradical alkylation of diverse $\mathrm{C}\left(\mathrm{sp}^{3}\right)-\mathrm{H}$ bonds $\uparrow$
}

\begin{abstract}
Xin Wen, (D) Yong Wang (D) and X. Peter Zhang (D) *
A new $\mathrm{C}-\mathrm{C}$ bond formation strategy based on enantioselective radical alkylation of $\mathrm{C}\left(\mathrm{sp}^{3}\right)-\mathrm{H}$ bonds via Co(॥)-based metalloradical catalysis has been demonstrated for stereoselective synthesis of chiral indolines. The Co(॥)-based system enables activation of aryldiazomethanes as radical precursors at room temperature for enantioselective intramolecular radical alkylation of broad types of $\mathrm{C}-\mathrm{H}$ bonds, constructing 2-substituted indolines in high yields with excellent enantioselectivities. In addition to chemoselectivity and regioselectivity, this Co(॥)-catalyzed alkylation features tolerance to functional groups and compatibility with heteroaryl substrates. Detailed mechanistic studies provide insight into the underlying stepwise radical pathway.
\end{abstract}

Received 30th March 2018

Accepted 12th May 2018

DOI: $10.1039 / \mathrm{c} 8 \mathrm{sc} 01476 \mathrm{k}$

rsc.li/chemical-science

such as aryldiazomethanes as radical precursors. ${ }^{8}$ Upon activation, the resulting $\alpha$-Co(III)-benzyl radicals could undergo radical addition to $\mathrm{C}=\mathrm{C}$ bonds and radical substitution for stereoselective radical cyclopropanation. ${ }^{8 a}$ Besides radical addition, we were interested in exploring the potential ability of $\alpha$-Co(III)-benzyl radicals for HAA that might lead to radical alkylation of $\mathrm{C}-\mathrm{H}$ bonds. Particularly, we were attracted to aryldiazomethane $\mathbf{1}^{\prime}$ with ortho-amino functionality and hypothesized that the corresponding $\alpha$-Co(III)-benzyl radical intermediate A would favor intramolecular HAA from the $\mathrm{C}-\mathrm{H}$ bonds at the distal 5-position to form $\varepsilon$-Co(III)-aminoalkyl radical $\mathbf{B}$, where the $\mathrm{C}$-centered radical would be stabilized by the lone pair of the adjacent nitrogen (Scheme 1). If the $\alpha$ aminoalkyl radical in $\mathbf{B}$ could proceed 5-exo-tet radical cyclization at the $\alpha$-carbon for $\mathrm{C}-\mathrm{C}$ bond formation in an asymmetric fashion, it would lead to a new catalytic system for enantioselective radical C-H alkylation to construct chiral 2-substituted indolines, which exist ubiquitously in natural and synthetic compounds (Fig. S1 in ESI $\dagger$ ). ${ }^{9}$

Tremendous efforts have been devoted to asymmetric synthesis of 2-substituted indolines due to their biological importance.$^{10}$ Among others, ${ }^{11}$ existing methods have explored strategies that are based on asymmetric hydrogenation of $\mathrm{C} 2=$ C3 bond, ${ }^{11 a, b}$ asymmetric alkylation at C2 position, ${ }^{11 c}$ asymmetric formation of C3-C3a bond, ${ }^{11 d, e}$ as well as asymmetric formation of N1-C7 ${ }^{11 f-h}$ and N1-C2 bonds. ${ }^{11 i}$ However, stereoselective construction of chiral 2-substituted indolines that is based on asymmetric formation of $\mathrm{C} 2-\mathrm{C} 3$ bond via $\mathrm{C}-\mathrm{H}$ alkylation has been less developed. ${ }^{12}$ This underdevelopment may be attributed to the inherent challenge for enantioselective formation of $\mathrm{C}-\mathrm{C}$ bonds between two $\mathrm{sp}^{3}$-carbons. To date, there is no previous report on asymmetric construction of 2substituted indolines through $\mathrm{C} 2\left(\mathrm{sp}^{3}\right)-\mathrm{C} 3\left(\mathrm{sp}^{3}\right)$ bond formation

Department of Chemistry, Merkert Chemistry Center, Boston College, Chestnut Hill, Massachusetts 02467, USA. E-mail: peter.zhang@bc.edu

$\dagger$ Electronic supplementary information (ESI) available. CCDC 1833864-1833865, 1833867-1833868. For ESI and crystallographic data in CIF or other electronic format see DOI: $10.1039 / \mathrm{c} 8 \mathrm{sc} 01476 \mathrm{k}$ 

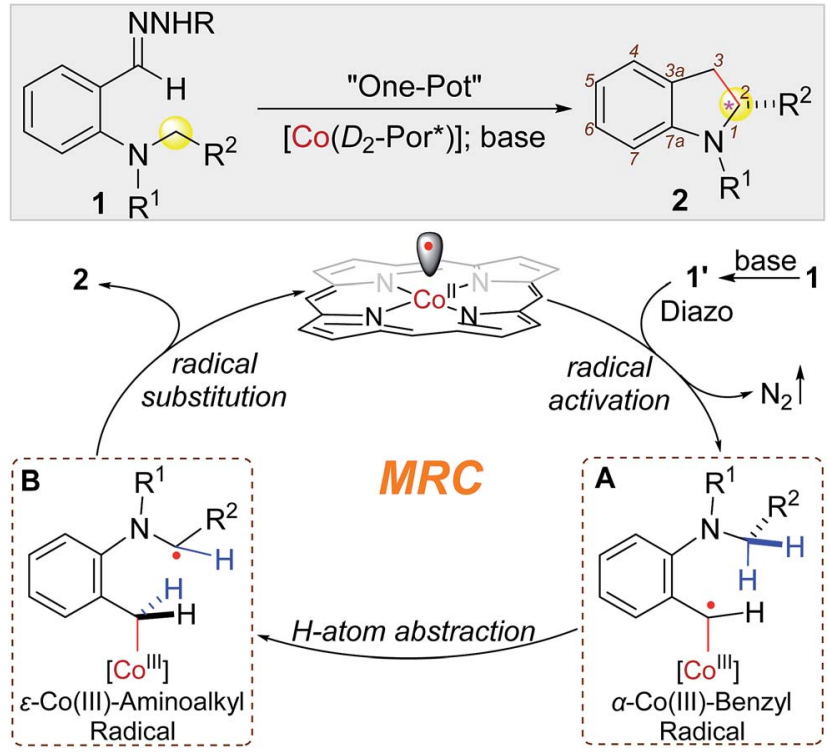

Scheme 1 Working proposal for construction of 2-substituted indolines by radical $\mathrm{C}-\mathrm{H}$ alkylation via $\mathrm{Co}(\mathrm{I})-\mathrm{MRC}$.

via stereoselective $\mathrm{C}\left(\mathrm{sp}^{3}\right)-\mathrm{H}$ alkylation using donor-type diazo compounds. As a new synthetic application of Co(II)-MRC, we herein report the development of the first catalytic system for asymmetric synthesis of 2-substituted indolines via enantioselective radical $\mathrm{C}-\mathrm{H}$ alkylation of aryldiazomethanes, which can be generated in situ from readily accessible aryl aldehydederived hydrazone precursors. Through the design of a new $D_{2}$-symmetric chiral amidoporphyrin, the Co(II)-catalyzed process can alkylate diverse types of $\mathrm{C}-\mathrm{H}$ bonds at room temperature to form chiral 2 -substituted indolines.

\section{Results and discussion}

At the outset, $o$-aminobenzaldehyde-derived hydrazone 1a was selected to examine the feasibility of $\mathrm{Co}(\mathrm{II})$-catalyzed radical $\mathrm{C}-\mathrm{H}$ alkylation (Table 1). It was found that $\mathrm{Co}$ (II) complex of $D_{2 \mathrm{~h}^{-}}$ symmetric achiral amidoporphyrin $[\mathrm{Co}(\mathbf{P 1})]\left(\mathbf{P 1}=3,5-\mathrm{Di}^{t} \mathrm{Bu}-\right.$ IbuPhyrin $)^{\mathbf{1 3}}$ was an effective metalloradical catalyst, delivering the desired 2-phenylindoline $\mathbf{2 a}$ in $81 \%$ yield even at room temperature (entry 1). The high yield implies that the in situ generation of the corresponding aryldiazomethane from 1a was facile and properly matched with the rate of its activation by the catalyst toward the $\mathrm{C}-\mathrm{H}$ alkylation. To achieve enantioselectivity, the use of the first-generation chiral catalyst $[\mathrm{Co}(\mathbf{P} 2)]$ $\left(\mathbf{P} 2=3,5-\mathrm{Di}^{t} \mathrm{Bu}-\mathrm{ChenPhyrin}\right)^{7 e}$ resulted in $\mathbf{2 a}$ in a similar yield with a low but significant enantioselectivity (entry 2). The asymmetric induction was improved without affecting the yield when the more sterically demanding catalyst $[\operatorname{Co}(\mathbf{P 3})](\mathbf{P 3}=2,6$ DiMeO-ChenPhyrin) was used (entry 3 ). This ligand buttressing effect prompted us to evaluate the second-generation catalyst $[\mathrm{Co}(\mathbf{P 4})]\left(\mathbf{P 4}=3,5-\mathrm{Di}{ }^{t} \mathrm{Bu}-\mathrm{Q}\right.$ ingPhyrin $) .{ }^{7 \boldsymbol{b}}$ Indeed, both the reactivity and enantioselectivity were significantly enhanced (entry 4). In a similar trend, when sterically more encumbered $[\mathrm{Co}(\mathbf{P 5})]$ (P5 = 2,6-DiMeO-QingPhyrin) was used, improvement in
Table 1 Optimization of Co(॥)-based catalytic system for enantioselective radical $\mathrm{C}-\mathrm{H}$ alkylation of aryldiazomethanes ${ }^{a}$

\begin{tabular}{llllll}
\hline & & & & \\
\hline
\end{tabular}
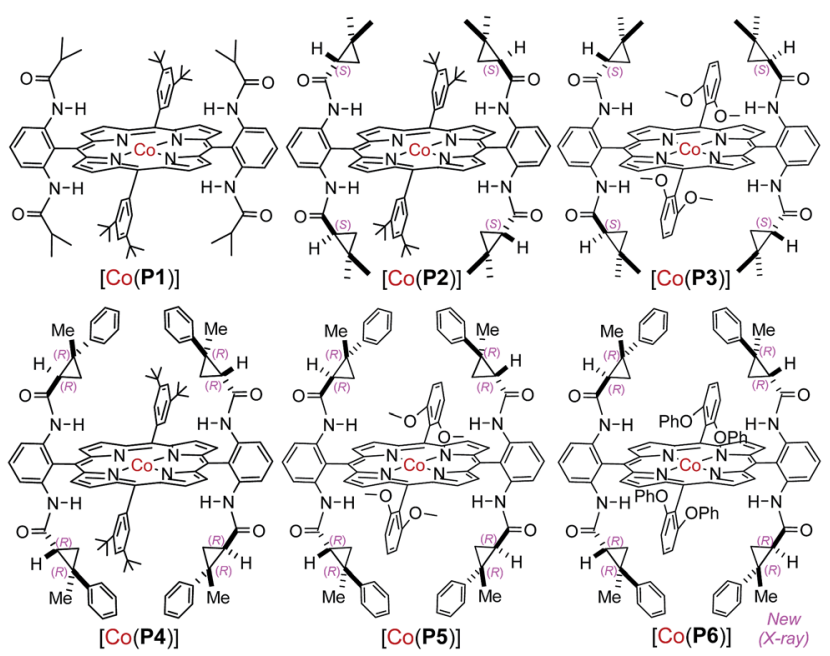

${ }^{a}$ Carried out with $1(0.1 \mathrm{mmol})$ in the presence of $\mathrm{Cs}_{2} \mathrm{CO}_{3}$ (2.0 equiv.) by [Co(Por)] $(2 \mathrm{~mol} \%)$ in solvent $(1.0 \mathrm{~mL})$; TPS $=2,4,6$-triisopropylphenyl sulfonyl. ${ }^{b}$ Isolated yields. ${ }^{c}$ Determined by chiral HPLC.

enantioselectivity continued (entry 5). To amplify such effect, we synthesized the new catalyst $[\mathrm{Co}(\mathbf{P 6})](\mathbf{P 6}=2,6-\mathrm{DiPhO}-$ QingPhyrin) by replacing the methoxy groups in P5 with phenoxy groups, which could catalyze 2 a formation in $82 \%$ yield with $66 \%$ ee (entry 6). Using [Co(P6)], we then examined the effect of $\mathrm{N}$-substituents in substrate 1 on the reaction. Change from $t$-butyl (1a) to ethyl (1b) to methyl (1c) carbamates led to a successive increase in both yield and ee, achieving almost quantitative yield and $86 \%$ ee in the case of $1 \mathrm{c}$ (entries 6-8). This outcome might be attributed to the potential hydrogen-bonding 
interaction between the carbonyl group of the carbamate and the amido group of the catalyst, which strengthens upon the decrease in sterics (Fig. S2 $\dagger$ ). Further investigation revealed that both polar and non-polar solvents were suitable (entries 8-13). The solvent of choice was methanol, affording 2-phenylindoline $2 \mathrm{c}$ in $92 \%$ yield with $94 \%$ ee (entry 12 ; see Table S1† for the effect of different sulfonyl groups).

Under the optimized conditions, the scope of $[\mathrm{Co}(\mathbf{P 6})]-$ catalyzed radical alkylation was evaluated by employing different $\mathrm{C}-\mathrm{H}$ substrates (Table 2). As demonstrated with substrates 1c-1k, benzylic $\mathrm{C}-\mathrm{H}$ bonds having varied electronic and steric properties could be effectively alkylated at room temperature in a highly enantioselective fashion, affording chiral 2-arylindolines $\mathbf{2 c - 2 k}$ in excellent yields (entries 1-9). The absolute configurations of $2 \mathbf{e}$ and $\mathbf{2} \mathbf{g}$ were established by X-ray crystal structural analysis as (R) (see ESI $\dagger$ ). It is noteworthy to mention that even the highly electron-deficient pentafluorobenzylic $\mathrm{C}-\mathrm{H}$ bond in $\mathbf{1 k}$ could successfully undergo

Table 2 [Co(P6)]-catalyzed enantioselective radical $\mathrm{C}-\mathrm{H}$ alkylation for construction of chiral 2-substituted indolines ${ }^{a}$

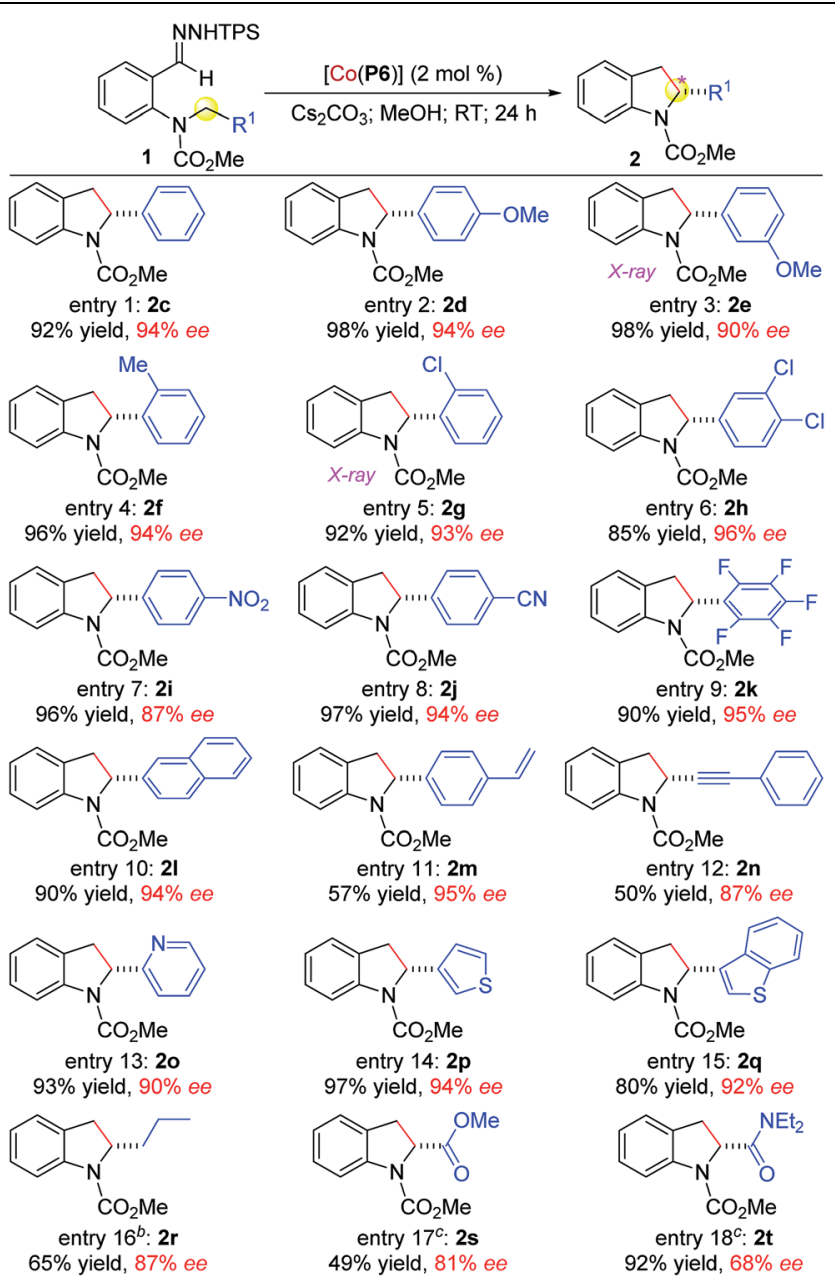

${ }^{a}$ Carried out with 1 ( $\left.0.1 \mathrm{mmol}\right)$ in the presence of $\mathrm{Cs}_{2} \mathrm{CO}_{3}$ (2.0 equiv.) in $\mathrm{MeOH}(1.0 \mathrm{~mL})$; isolated yields; ee was determined by chiral HPLC. ${ }^{b}$ At $60{ }^{\circ} \mathrm{C} .{ }^{\circ}$ At $40{ }^{\circ} \mathrm{C}$. radical alkylation, forming $2 \mathbf{k}$ in $90 \%$ yield with $95 \%$ ee (entry 9). The system could also alkylate $\mathrm{C}-\mathrm{H}$ bonds adjacent to other arenes as shown with the 2-naphthyl-based substrate $\mathbf{1 l}$ (entry 10). Besides $-\mathrm{NO}_{2}$ and - $\mathrm{CN}$ functionalities (entries 7 and 8), the alkylation tolerated both alkenyl and alkynyl groups, as demonstrated by the stereoselective formation of $\mathbf{2 m}$ and $\mathbf{2 n}$ without complications from potential reactions with the $\mathrm{C}=\mathrm{C}$ and $\mathrm{C} \equiv \mathrm{C}$ bonds, respectively (entries 11 and 12). Notably, this system was equally effective for alkylation of $\mathrm{C}-\mathrm{H}$ bonds next to heteroarenes, such as pyridine (10), thiophene (1p), and benzothiophene (1q), providing 2-heteroarylindolines $\mathbf{2 0 - 2 q}$ in high yields and enantioselectivities (entries 13-15). Given that both heteroarene and indoline are prevalent structural elements in bioactive natural and synthetic compounds, the access of these linked biheterocyclic compounds in high enantiopurity may find applications in pharmaceutical research and development. Furthermore, non-activated $\mathrm{C}-\mathrm{H}$ bonds could also be alkylated, as exemplified by the regioselective 1,5alkylation of 1r, forming 2-propylindoline (2r) in 65\% yield with $87 \%$ ee although $60{ }^{\circ} \mathrm{C}$ was needed (entry 16). The alkylation was further highlighted by its applicability to even $\mathrm{C}-\mathrm{H}$ bonds that are directly attached to electron-withdrawing groups. For example, electron-poor $\mathrm{C}-\mathrm{H}$ bonds that are adjacent to ester (1s) and amide (1t) groups were smoothly alkylated at $40{ }^{\circ} \mathrm{C}$ to furnish the 2-ester (2s)- and 2-amido (2t)-indolines in varied yields and enantioselectivities (entries 17 and 18). These results manifested the low sensitivity of the Co(II)-based alkylation to the electronic properties of $\mathrm{C}-\mathrm{H}$ bonds, which are consistent with its underlying radical mechanism.

To gain insight into the underlying mechanism of this $\mathrm{Co}(\mathrm{II})-$ catalyzed $\mathrm{C}-\mathrm{H}$ alkylation, a set of mechanistic experiments were conducted (Scheme 2). First, the effect of TEMPO was examined. Addition of TEMPO to the reaction of benzyl $\mathrm{C}-\mathrm{H}$ substrate 1c by achiral catalyst $[\mathrm{Co}(\mathbf{P 1})]$ resulted in no formation of $\mathrm{C}-\mathrm{H}$ alkylation product 2c. Instead, compound $( \pm)$-3c was isolated in $70 \%$ yield, whose structure was confirmed by X-ray analysis to contain two TEMPO units at the 1- and 5-positions (Scheme 2a). The formation of $( \pm)-3 c$ is indicative of the existence of the initial $\alpha$-Co(III)-benzyl radical (1c-A) as well as the resulting $\varepsilon$ Co(III)-aminoalkyl radical (1c-B) from 1,5-HAA, which was presumably capped subsequently by TEMPO at the $\varepsilon$-position through radical recombination to generate intermediate 1c-C and then followed by radical substitution with second TEMPO at the $\alpha$-position to break the weak $\mathrm{Co}(\mathrm{III})-\mathrm{C}$ bond for final production of $( \pm)-3 c$. To gain information on stereochemistry, the same reaction was performed with chiral catalyst $[\mathrm{Co}(\mathbf{P 6})]$ (Scheme 2a). The same bis-TEMPO-capped compound (-)-3c was generated, but in a much higher yield of $90 \%$ and, remarkably, with $93 \%$ ee. The fact that the enantioselectivity for the $\mathrm{C}-\mathrm{O}$ bond formation $(93 \%$ ee) of the TEMPO-capped product (-)-3c was almost identical to the one observed for the $\mathrm{C}-\mathrm{C}$ bond formation ( $94 \%$ ee) of the $\mathrm{C}-\mathrm{H}$ alkylation product $2 \mathrm{c}$ in the absence of TEMPO (Table 2: entry 1) implies that the prochiral $\alpha$-aminoalkyl radical in $\mathbf{1 c}$-B was confined inside the chiral pocket of $[\mathrm{Co}(\mathbf{P 6})]$ to adapt a stable, well-defined configuration. In addition, the resulting $\mathrm{Co}$ (III)-supported alkyl radical intermediates from the reaction of $1 \mathbf{c}$ by $[\mathrm{Co}(\mathbf{P 1})]$ in the absence 
a) Effect of TEMPO on Benzylic C-H Reaction: Stereochemistry

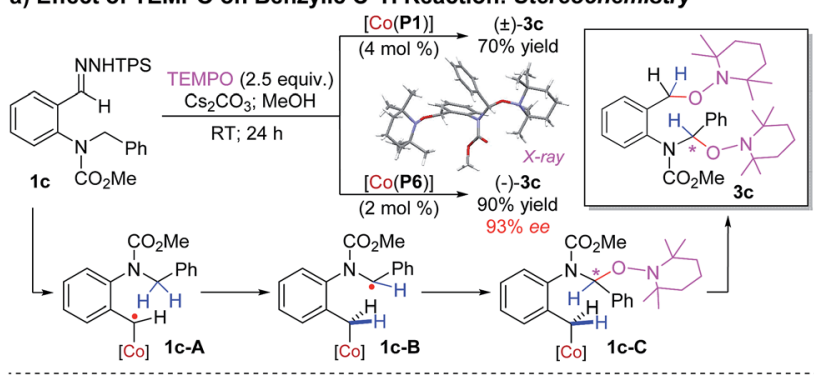

b) Effect of TEMPO on Allylic C-H Reaction:Olefin Isomerization

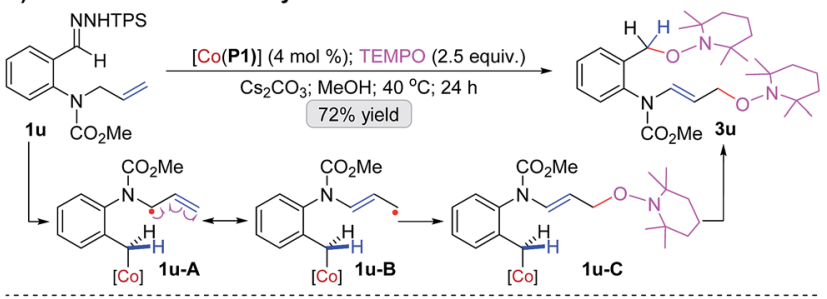

c) Effect of TEMPO on Cyclopropylmethyl C-H Reaction: Ring Opening

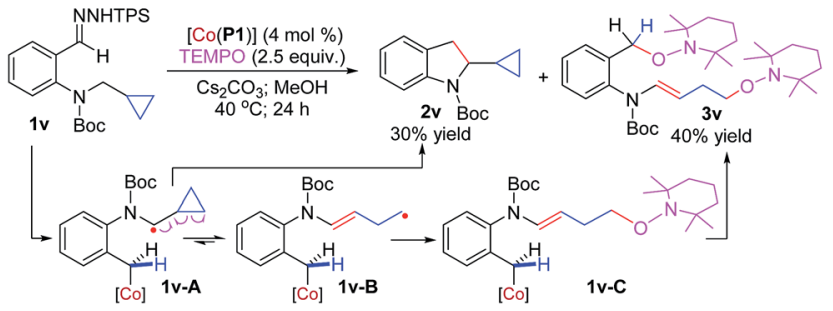

Scheme 2 Mechanistic studies on Co(I)-catalyzed intramolecular radical $\mathrm{C}-\mathrm{H}$ alkylation of $\mathrm{O}$-aminoaryldiazomethanes.

of TEMPO could be directly detected by HRMS (Fig. S3†) and also spin-trapped by phenyl $N$-tert-butylnitrone (PBN) to exhibit the characteristic EPR signals (Fig. S4†).

To gather further evidence for the stepwise radical mechanism, we designed specific substrates as radical probes to shed light on the nature of $\varepsilon$-Co(III)-aminoalkyl radical intermediates. First, allylic $\mathrm{C}-\mathrm{H}$ substrate $\mathbf{1} \mathbf{u}$ was prepared as a radical resonance probe to evaluate potential olefin isomerization via the resulting allylic radical intermediate after 1,5-HAA (Scheme 2b). As observed for 1c (Scheme 2a), a similar bis-TEMPO-capped compound $3 \mathbf{u}$ was isolated in $72 \%$ yield without formation of the corresponding $\mathrm{C}-\mathrm{H}$ alkylation product (Scheme $2 \mathrm{~b}$ ). Characterizations of $3 \mathbf{u}$ revealed that the $\mathrm{C}=\mathrm{C}$ double bond was isomerized from the terminal to internal position (Scheme $2 b$ ). Clearly, the resulting $\varepsilon$-Co(III)-aminoalkyl radical, which can be represented by its two resonance forms $1 \mathbf{1}-\mathbf{A}$ and $\mathbf{1 u}-\mathbf{B}$ as an allylic radical, was captured by TEMPO to give intermediate 1u$\mathbf{C}$ and then underwent further radical substitution with second TEMPO to deliver $3 \mathbf{u}$. The predominant production of $3 \mathbf{u}$ is presumably a result of the much faster capping rate of $\mathbf{1 u}-\mathbf{B}$ (a primary radical) than 1u-A (a secondary radical) by TEMPO radical. Second, substrate $\mathbf{1 v}$ bearing a cyclopropyl ring was synthesized as a radical clock to examine ring-opening of the cyclopropylmethyl radical generated from 1,5-HAA (Scheme 2c). Interestingly, the reaction of $\mathbf{1} \mathbf{v}$ by $[\mathrm{Co}(\mathbf{P} \mathbf{1})]$ in the presence of TEMPO resulted in the formation of bis-TEMPO-capped compound $3 \mathbf{v}$ in $40 \%$ yield as well as the $\mathrm{C}-\mathrm{H}$ alkylation product $2 \mathbf{v}$ in $30 \%$ yield. Obviously, the corresponding $\varepsilon$ - $\mathrm{Co}(\mathrm{III})$ aminoalkyl radical intermediate 1v-A underwent two competitive pathways. While its radical substitution formed $2 \mathbf{v}$, the cyclopropylcarbinyl radical in $\mathbf{1 v}$-A also proceeded ring-opening competitively to generate homoallylic alkyl radical $\mathbf{1 v}-\mathbf{B}$, which was transformed to the enamine $3 \mathbf{v}$ upon two sequential captures by TEMPO via intermediate $\mathbf{1 v}$-C. The fact that $2 \mathbf{v}$ and $3 \mathbf{v}$ were produced in similar yields indicated that the forming rate of $\mathrm{C} 2-\mathrm{C} 3$ bond via radical substitution to construct the indoline ring was fast. ${ }^{14}$

\section{Conclusions}

In summary, the new Co(II)-based metalloradical system for enantioselective radical alkylation of $\mathrm{C}\left(\mathrm{sp}^{3}\right)-\mathrm{H}$ bonds has been developed for stereoselective synthesis of chiral indolines through asymmetric $\mathrm{C} 2-\mathrm{C} 3$ bond formation. Supported by the new ligand 2,6-DiPhO-QingPhyrin, this Co(II)-catalyzed system can activate in situ generated ortho-aminoaryldiazomethanes at room temperature for stereoselective radical alkylation of different types of $\mathrm{C}\left(\mathrm{sp}^{3}\right)-\mathrm{H}$ bonds with varied electronic and steric properties. In addition to chemoselectivity and regioselectivity, this radical system features functional group tolerance as well as compatibility with heteroaryl units. It represents a new synthetic application of $\mathrm{Co}(\mathrm{II})$-based MRC and offers a streamlined construction of chiral 2-substituted indolines from readily available starting materials.

\section{Conflicts of interest}

There are no conflicts to declare.

\section{Acknowledgements}

We are grateful for financial support by NSF (CHE-1624216) and NIH (R01-GM102554).

\section{References}

1 (a) C. Chatgilialoglu and A. Studer, Encyclopedia of radicals in chemistry, biology, and materials, John Wiley \& Sons, Chichester, West Sussex, Hoboken, N.J., 2012; (b) D. P. Curran, N. A. Porter and B. Giese, Stereochemistry of radical reactions: concepts, guidelines, and synthetic applications, John Wiley \& Sons, 2008; (c) S. Z. Zard, Radical reactions in organic synthesis, Oxford University Press, Oxford, 2003; (d) M. Yan, J. C. Lo, J. T. Edwards and P. S. Baran, J. Am. Chem. Soc., 2016, 138, 12692-12714; (e) M. H. Shaw, J. Twilton and D. W. C. MacMillan, J. Org. Chem., 2016, 81, 6898-6926.

2 (a) Q. Lu and F. Glorius, Angew. Chem., Int. Ed., 2017, 56, 4951; (b) X.-Q. Hu, J.-R. Chen and W.-J. Xiao, Angew. Chem., Int. Ed., 2017, 56, 1960-1962; (c) G. J. Choi, Q. Zhu, D. C. Miller, C. J. Gu and R. R. Knowles, Nature, 2016, 539, 268-271; (d) J. C. K. Chu and T. Rovis, Nature, 2016, 539, 272-275; (e) F. Burg, M. Gicquel, S. Breitenlechner, A. Pöthig and T. Bach, Angew. Chem., Int. Ed., 2018, 57, 2953-2957; (f) 
W. Zhang, F. Wang, S. D. McCann, D. H. Wang, P. H. Chen, S. S. Stahl and G. S. Liu, Science, 2016, 353, 1014-1018.

3 (a) R. Brimioulle, D. Lenhart, M. M. Maturi and T. Bach, Angew. Chem., Int. Ed., 2015, 54, 3872-3890; (b) M. P. Sibi, S. Manyem and J. Zimmerman, Chem. Rev., 2003, 103, 3263-3296; (c) N. Kern, M. P. Plesniak, J. J. W. McDouall and D. J. Procter, Nat. Chem., 2017, 9, 1198-1204; (d) Q. M. Kainz, C. D. Matier, A. Bartoszewicz, S. L. Zultanski, J. C. Peters and G. C. Fu, Science, 2016, 351, 681-684; (e) T. R. Blum, Z. D. Miller, D. M. Bates, I. A. Guzei and T. P. Yoon, Science, 2016, 354, 1391-1395; (f) J.-S. Lin, X.-Y. Dong, T.-T. Li, N.-C. Jiang, B. Tan and X.-Y. Liu, J. Am. Chem. Soc., 2016, 138, 9357-9360; (g) H. Huo, X. Shen, C. Wang, L. Zhang, P. Rose, L.-A. Chen, K. Harms, M. Marsch, G. Hilt and E. Meggers, Nature, 2014, 515, 100-103; (h) R. Zhu and S. L. Buchwald, Angew. Chem., Int. Ed., 2013, 52, 12655-12658.

4 For reviews and highlights on Co(II)-based MRC, see: $(a)$ H. Miyabe, A. Kawashima, E. Yoshioka and S. Kohtani, Chem.-Eur. J., 2017, 23, 6225-6236; (b) A. Studer and D. P. Curran, Angew. Chem., Int. Ed., 2016, 55, 58-102; (c) H. Pellissier and H. Clavier, Chem. Rev., 2014, 114, 27752823; (d) H. J. Lu and X. P. Zhang, Chem. Soc. Rev., 2011, 40, 1899-1909; (e) M. P. Doyle, Angew. Chem., Int. Ed., 2009, 48, 850-852.

5 Select examples on Ti(III)-MRC, see: (a) Y. Q. Zhang, E. Vogelsang, Z. W. Qu, S. Grimme and A. Gansäuer, Angew. Chem., Int. Ed., 2017, 56, 12654-12657; (b) W. Hao, X. Wu, J. Z. Sun, J. C. Siu, S. N. MacMillan and S. Lin, J. Am. Chem. Soc., 2017, 139, 12141-12144; (c) A. Gansäuer, S. Hildebrandt, E. Vogelsang and R. A. Flowers II, Dalton Trans., 2016, 45, 448-452; (d) A. Gansäuer, A. Fleckhaus, M. A. Lafont, A. Okkel, K. Kotsis, A. Anoop and F. Neese, J. Am. Chem. Soc., 2009, 131, 16989-16999.

6 For experimental and theoretical studies on the radical mechanism involving $\alpha$-Co(III)-alkyl radical (also known as $\mathrm{Co}(\mathrm{III})$-carbene radical) intermediates for olefin cyclopropanation, see: (a) H. J. Lu, W. I. Dzik, X. Xu, L. Wojtas, B. de Bruin and X. P. Zhang, J. Am. Chem. Soc., 2011, 133, 8518-8521; (b) J. L. Belof, C. R. Cioce, X. Xu, X. P. Zhang, B. Space and H. L. Woodcock, Organometallics, 2011, 30, 2739-2746; (c) W. I. Dzik, X. Xu, X. P. Zhang, J. N. H. Reek and B. de Bruin, J. Am. Chem. Soc., 2010, 132, 10891-10902.

7 For select examples on asymmetric radical transformations via Co(III)-alkyl radical intermediates, see: (a) X. Xu, S. F. Zhu, X. Cui, L. Wojtas and X. P. Zhang, Angew. Chem., Int. Ed., 2013, 52, 11857-11861; (b) X. Xu, H. J. Lu, J. V. Ruppel, X. Cui, S. L. de Mesa, L. Wojtas and X. P. Zhang, J. Am. Chem. Soc., 2011, 133, 15292-15295; (c) X. Cui, X. Xu, H. J. Lu, S. F. Zhu, L. Wojtas and X. P. Zhang, J. Am. Chem. Soc., 2011, 133, 3304-3307; (d) S. F. Zhu, X. Xu, J. A. Perman and X. P. Zhang, J. Am. Chem. Soc., 2010, 132, 12796-12799; (e) Y. Chen, K. B. Fields and X. P. Zhang, J. Am. Chem. Soc., 2004, 126, 14718-14719; (f)
X. Cui, X. Xu, L. M. Jin, L. Wojtas and X. P. Zhang, Chem. Sci., 2015, 6, 1219-1224.

8 (a) Y. Wang, X. Wen, X. Cui, L. Wojtas and X. P. Zhang, J. Am. Chem. Soc., 2017, 139, 1049-1052; (b) B. G. Das, A. Chirila, M. Tromp, J. N. H. Reek and B. d. Bruin, J. Am. Chem. Soc., 2016, 138, 8968-8975; (c) N. D. Paul, S. Mandal, M. Otte, X. Cui, X. P. Zhang and B. de Bruin, J. Am. Chem. Soc., 2014, 136, 1090-1096.

9 (a) D. Zhang, H. Song and Y. Qin, Acc. Chem. Res., 2011, 44, 447-457; (b) L. A. T. Cleghorn, S. Albrecht, L. Stojanovski, F. R. J. Simeons, S. Norval, R. Kime, I. T. Collie, M. De Rycker, L. Campbell, I. Hallyburton, J. A. Frearson, P. G. Wyatt, K. D. Read and I. H. Gilbert, J. Med. Chem., 2015, 58, 7695-7706.

10 For a review on asymmetric synthesis of 2-substituted indolines, see: S. Anas and H. B. Kagan, Tetrahedron: Asymmetry, 2009, 20, 2193-2199.

11 For select examples on asymmetric synthesis of 2substituted indolines, see: (a) Z. Yang, F. Chen, Y. He, N. Yang and Q.-H. Fan, Angew. Chem., Int. Ed., 2016, 55, 13863-13866; (b) T. Touge and T. Arai, J. Am. Chem. Soc., 2016, 138, 11299-11305; (c) K. M. B. Gross, Y. M. Jun and P. Beak, J. Org. Chem., 1997, 62, 7679-7689; (d) T. Saget, S. J. Lemouzy and N. Cramer, Angew. Chem., Int. Ed., 2012, 51, 2238-2242; (e) D. Katayev, M. Nakanishi, T. Burgi and E. P. Kündig, Chem. Sci., 2012, 3, 1422-1425; (f) A. Minatti and S. L. Buchwald, Org. Lett., 2008, 10, 2721-2724; $(g)$ R. Viswanathan, E. N. Prabhakaran, M. A. Plotkin and J. N. Johnston, J. Am. Chem. Soc., 2003, 125, 163-168; (h) S. Wagaw, R. A. Rennels and S. L. Buchwald, J. Am. Chem. Soc., 1997, 119, 8451-8458; (i) T. W. Liwosz and S. R. Chemler, J. Am. Chem. Soc., 2012, 134, 2020-2023; (j) J. I. Murray, N. J. Flodén, A. Bauer, N. D. Fessner, D. L. Dunklemann, O. Bob-Egbe, H. S. Rzepa, T. Bürgi, J. Richardson and A. C. Spivey, Angew. Chem., Int. Ed., 2017, 56, 5760-5764; (k) E. Ascic and S. L. Buchwald, J. Am. Chem. Soc., 2015, 137, 4666-4669; (l) E. E. Maciver, S. Thompson and M. D. Smith, Angew. Chem., Int. Ed., 2009, 48, 9979-9982; $(m)$ F. O. Arp and G. C. Fu, J. Am. Chem. Soc., 2006, 128, 14264-14265.

12 (a) M. Santi, S. T. R. Müller, A. A. Folgueiras-Amador, A. Uttry, P. Hellier and T. Wirth, Eur. J. Org. Chem., 2017, 2017, 1889-1893; (b) S. Lee, H.-J. Lim, K. L. Cha and G. A. Sulikowski, Tetrahedron, 1997, 53, 16521-16532; (c) C. Soldi, K. N. Lamb, R. A. Squitieri, M. González-López, M. J. Di Maso and J. T. Shaw, J. Am. Chem. Soc., 2014, 136, 15142-15145; (d) A. S. Karns, M. Goswami and B. de Bruin, Chem. Eur. J., 2018, 24, 5253-5258; (e) Y. Wang, X. Wen, X. Cui and X. P. Zhang, J. Am. Chem. Soc., 2018, 140, 47924796.

13 J. V. Ruppel, J. E. Jones, C. A. Huff, R. M. Kamble, Y. Chen and X. P. Zhang, Org. Lett., 2008, 10, 1995-1998.

14 For the rate constant of ring-opening of the parent cyclopropylmethyl radical, see: V. W. Bowry, J. Lusztyk and K. U. Ingold, J. Am. Chem. Soc., 1991, 113, 5687-5698. 